\title{
20
}

\section{Identification and characterization of field sites for genetic control of disease vectors}

\author{
Bart G.J. Knols ${ }^{\#}$ and Hervé Bossin ${ }^{\#}$
}

\begin{abstract}
Genetic control of disease vectors consists of a large variety of approaches. Each of these bring along an often-substantial number of prerequisites in order to stand a chance of being successful. Of the large number of trials documented, only few have taken the scale and scope of operation to sustain long-term area-wide benefits. Broadly speaking, two categories of issues will be faced by any genetic control programme when moving from the laboratory to the field: those that relate to biological and/or environmental factors and those that relate to stakeholder power. The ongoing debate on genetically engineered crops has heightened the interest of many (often antagonistic) stakeholders in the possible impact that biotechnological advances may have on society and the environment, which necessitates a much larger impetus towards stakeholder management. Identification of suitable field sites for anticipated genetic-control trials therefore requires a stepwise approach, which is outlined in this chapter. A coordinating entity, consisting of stakeholders from disease-endemic countries (DECs) and (inter)national experts, is urgently needed to provide support to governments in their decision-making process regarding geneticcontrol trials. Such entity should also serve a mediating function between researchers, end-users and influential stakeholders (e.g. press) in order to further the potential of biotechnological developments. Failure to steer this process efficiently may result in substantial opposition and stalling of progress, similar to hindrances experienced with the introduction of transgenic crops in the European Union.
\end{abstract}

Keywords: genetic control; transgenesis; field site selection; biological variables; environmental variables; stakeholder management

\section{Introduction}

The ongoing development of genetically modified disease vectors (or their symbionts) for application in genetic-control programmes against major tropical diseases such as malaria (Ito et al. 2002; Alphey et al. 2002), dengue (Olson et al. 1996), and Chaga disease (Beard et al. 2002), is gradually advancing to a stage where scientists involved are planning field trials or, more in the short term, semi-field evaluations in contained near-natural environments. This gradual transition of research efforts from the laboratory to field environments raises a number of

\footnotetext{
\# International Atomic Energy Agency (IAEA), Agency’s Laboratories Seibersdorf, A-2444 Seibersdorf, Austria, and Laboratory of Entomology, Wageningen University and Research Centre, PO Box 8031, 6700 EH Wageningen, The Netherlands. E-mail: B.Knols@IAEA.org; H.Bossin@IAEA.org
} 
important issues like ELSI (ethical, legal and social issues; see Macer (2003) and Touré and Knols (in press, Chapter 23), and also the selection of appropriate field sites. Both site identification and characterization are discussed in this paper.

A priori, it can be noted that previous genetic-control trials (e.g. employing cytoplasmic incompatibility (CI) (Laven 1967), chromosomal translocations (Curtis 1968; Laven 1972; Lounibos 2003) and the sterile-insect technique (SIT) (Knipling 1955; Klassen and Curtis in press), etc.), amongst other approaches, have addressed many analogous problems related to site selection and characterization, albeit without the genetic-engineering component that adds new and unique concerns. The following sections focus on GM mosquitoes, though most concepts apply similarly to other disease vectors.

\section{Biological and environmental prerequisites}

Laven's CI trials (1967) in Myanmar were conducted in a small village surrounded by rice fields, where the target pest (Culex pipiens fatigans) did not occur. In Kenya, genetic-control trials against Ae. aegypti in the 1970s focused on villages and a small area surrounding them (Lounibos 2003). The necessity for applying genetic control against isolated populations remains valid today. It has been proposed to target Anopheles arabiensis populations in urban areas surrounded by An. gambiae s.s. or urban An. stephensi populations surrounded by An. culicifacies (Curtis 2003; Kristan et al. 2003). Others have suggested going beyond 'ecological islands' described above, and move to physical islands. Genetic-control trials have delivered dramatic successes through eradication of target pests, such as the eradication of Glossina austeni from the island of Zanzibar (Msangi et al. 2000).

With regard to the application of GM approaches for disease-vector control, further containment (in terms of selecting isolated populations) is needed to overcome potential adverse effects of the introduction of GM insects. The choice for physical islands, far from mainland vector populations, seems the best option in that regard (G. Lanzaro, pers. comm.).

Beyond (1) geographic isolation, there are several more key factors affecting the selection of a field site and the target species, such as: (2) occurrence in a narrow geographic range and (3) appropriately sized area (small enough to be manageable, large enough to be convincing); presence of (4) panmictic populations (i.e. all individuals within the population are potential recombination partners) of (5) one vector species (although another closely related non-transmitting species may be useful as a 'control'); the target species occurs in relatively (6) low density and can be suppressed with existing vector control tools; and (7) disease transmission, in order to measure the public-health impact resulting from the intervention.

These biological prerequisites should serve as the first criteria when selecting a field site. Secondary criteria include (8) site accessibility and availability of research infrastructure, and the availability of (9) detailed entomological and epidemiological information.

Additionally, the release of genetically altered mosquitoes necessitates further precautionary measures as outlined by Spielman, Beier and Kiszewski (2002). In their view, releases should not be permitted unless: (1) the nuisance caused by released organisms remains lower than that caused by ambient vector organisms; (2) the release results in no increase in abundance of haematophagous arthropods; (3) the release requires no reduction in ongoing health-promoting activities; (4) the risk of transmission of microbes other than the target pathogen would not increase; (5) the 
release does not compromise future interventions against the target disease; and (6) any improved state of health of people living in the release site is sustainable. In addition, a release must pose no environmental threat due to horizontal transfer of transgenes to predators or other organisms in the release site.

Clearly, both of the above lists result in only a limited number of potential field sites that may be suitable for proof-of-principle experimentation beyond the confines of the laboratory. Arguably, biological and environmental prerequisites should be given priority when identifying potential sites, as additional requirements (e.g. research infrastructure, local capacity and opportunities for collaboration) can be obtained and/or developed. Nevertheless, it should be clear from the onset that research efforts relating to the former are futile if the latter are insufficiently addressed. A perfect field site may be useless if consent from major stakeholders cannot be obtained. Ideally, therefore, both processes should be undertaken simultaneously.

\section{Stakeholder management}

\section{Public outreach}

Given the controversy that has already been associated with projects involving genetic engineering, it is reasonable to expect that future research efforts will draw the attention and concern of people who are not directly involved with the field studies (Gaskell et al. 2002). Studies on risks associated with large-scale technological and scientific activity are capable of attracting significant public opposition (Beck 1992), and it is becoming clear that involving broad sectors of the public in discussion, planning and even conduct of these activities may be the only effective way to cope with this challenge (National Research Council NRC 1996).

Community consent is essential to this, as to any attempt to release genetically modified organisms requires (Knols and Scott 2003). Given the absence of any existing mechanisms for assisting with this process (Pew Initiative on Food and Biotechnology 2005), investigators currently rely on approaches used elsewhere, adapt them to local culture and introduce them through national counterparts and authorities. The ethical component of forthcoming projects relates to both potential risks and public perception and opinion of the project and its research components. Regretfully, the ongoing process of identifying potential field sites currently lacks a policy framework that adequately protects against possible public-health and environmental risks. Bearing in mind the negative outcomes of certain (anticipated) massive releases of mosquitoes in the past (Desowitz 1993; Oh New Delhi, Oh Geneva (editorial) 1975; WHO 1976), a stepwise approach toward the residents of potential study sites needs urgent development.

\section{Oversight mechanism}

Considering the fact that various research groups are actively seeking collaboration in potential field sites, and given the fact that research activities in preparation for possible releases are underway (see for instance Chen et al. 2004), absence of oversight of these activities may harm the entire endeavour if inadequately conducted. A clear outcome of the Nairobi meeting (see Chapter 1) was the recognized need to oversee and coordinate field-related research. It was proposed to set up a steering committee (Figure 1) that will consist of GMO experts, public-health entomologists, representatives of ministries, social scientists and ELSI experts, WHO regional and Geneva representatives, etc. 


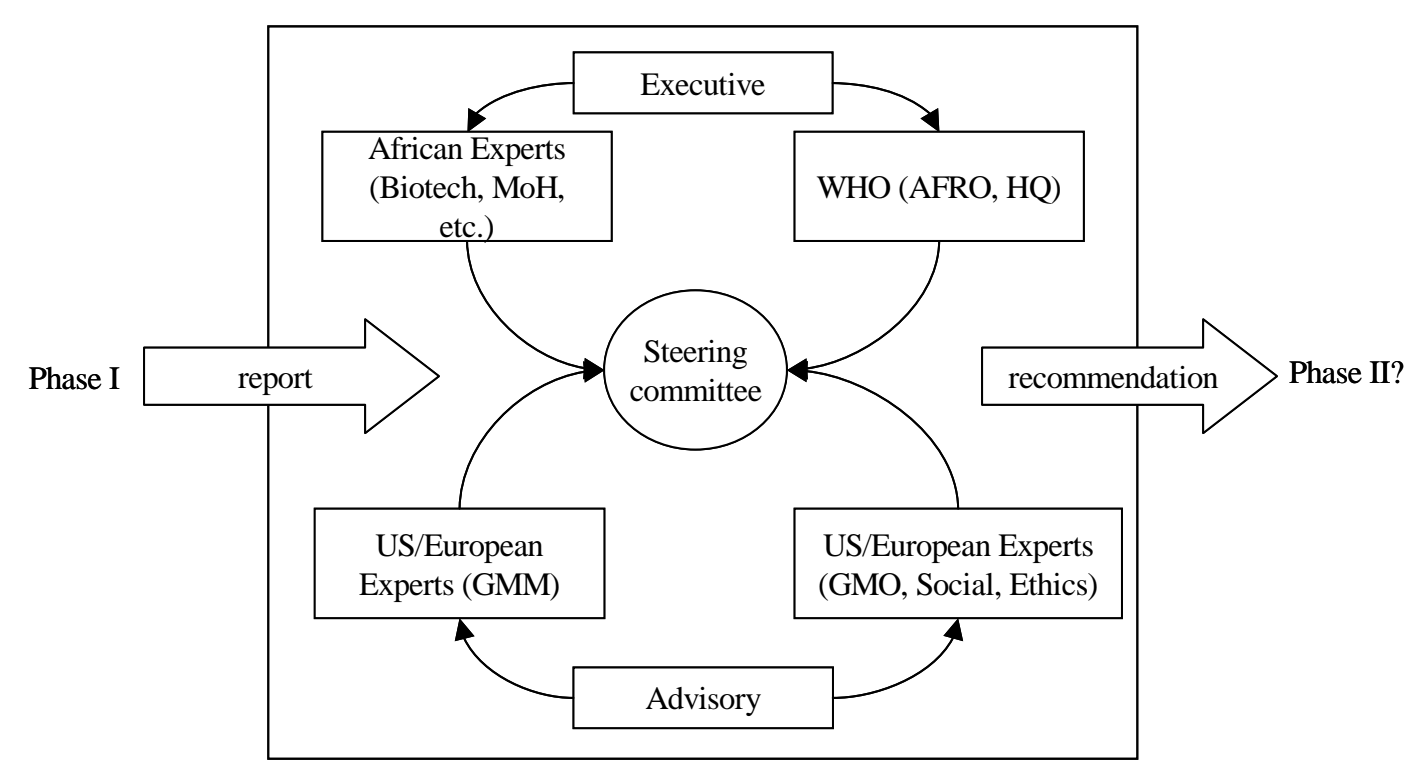

Figure 1. A proposed mechanism to guide the transitional phases for implementation of genetic-control trials from laboratory to field settings

The group, which should remain impartial and without conflict of interest, could have its members assigned to either the executive or advisory part of the committee. Larger representation of disease-endemic country representatives with executive power should be foreseen as a means to transfer 'ownership'. This expert panel should review project progress at defined intervals and have the penultimate decision-making power to endorse phase advancement (Phase I (laboratory cage) to II to III trials (semi-field systems in tropics) based on written documents (for more details of this process, see Chapter 16). The committee, in turn, would justify its decisions by reporting to the governments of the countries involved, funding agencies, and other relevant stakeholders they identify. Further justification for this approach has recently been published (Mshinda et al. 2004; Pew Initiative on Food and Biotechnology 2005) and has significant analogies with the (former) African Malaria Vaccine Testing Network (now residing under the African Malaria Network, AMANET) that oversees and evaluates all vaccine trials in Africa.

Perhaps the most significant challenge in terms of GM insect development and implementation is the full participation of and genuine collaboration with partner institutions in disease-endemic settings that meet the above criteria. For instance, it is likely that the suitability of certain island settings will be countered by the absence of appropriate institutional frameworks and local competence. In view of this, it seems appropriate to develop more generic guidelines for GM insect implementation irrespective of the field site/country involved. Again, the regulatory framework proposed above seems best suited for this task (Mshinda et al. 2004).

\section{Field site characterization}

Specific research topics related to field site selection and characterization should follow an evaluation of the existing human resources and scientific/public-health infrastructure at the chosen sites, and include:

(1)collection of basic ecological and biological data of the target species, including relative population densities, (adult and larval) distribution patterns and an 
assessment of the role of the target species in disease transmission (Touré et al. 1998; Scott et al. 2002; Taylor and Manoukis 2003; Billingsley et al. in press);

(2)an assessment of the degree to which the target population is genetically isolated from surrounding populations and a description of the genetic structure of the population (see Chapter 14 for details and methods);

(3)Creation of a geographic information system (GIS) that describes the ecology of each site and is fully integrated with information from the ecology and populationgenetics studies.

It is important to note at this juncture, that these activities benefit not only planned genetic vector-control interventions, but any vector-control programme. Essential though, is recognition of the fact that the tools for this kind of field research are available and that field site identification and preparation is therefore a key activity underpinning the transition of research from the bench to the field.

\section{Conclusions}

Given the long list of prerequisites that determine selection of appropriate field sites for trials to evaluate GM insects in Phase II and III settings (Chapter 16), it is unlikely that many such sites will be identified. Currently this selection process is not monitored and in the hands of individual scientists. Given the intricacies of this process and the difficulties associated with stakeholder management, both general guidelines and an oversight mechanism are urgently needed. Previous investment in the development of GM insects warrants careful progression towards moving technology and capacity to DEC settings. Failure to do so may result in significant delays or even blockage to evaluate the full potential of these approaches to curb some of the world's most debilitating diseases.

\section{References}

Alphey, L., Beard, C.B., Billingsley, P., et al., 2002. Malaria control with genetically manipulated insect vectors. Science, 298 (5591), 119-121.

Beard, C.B., Cordon-Rosales, C. and Durvasula, R.V., 2002. Bacterial symbionts of the triatominae and their potential use in control of Chagas disease transmission. Annual Review of Entomology, 47, 123-141.

Beck, U., 1992. Risk society: towards a new modernity. Sage Publications, London.

Billingsley, P.F., Charlwood, J.D. and Knols, B.G.J., in press. Rapid assessment of malaria risk using entomological techniques: taking an epidemiological snapshot. In: Takken, W., Martens, P. and Bogers, R.J. eds. Environmental change and malaria risk: global and local implications. Springer, Dordrecht. Wageningen UR Frontis Series no. 9. [http://library.wur.nl/frontis/ environmental_change/06_billingsley.pdf]

Chen, H., Minakawa, N., Beier, J.C., et al., 2004. Population genetic structure of Anopheles gambiae mosquitoes on Lake Victoria islands, west Kenya. Malaria Journal, 3 (1), 48. [http://www.malariajournal.com/content/3/1/48]

Curtis, C.F., 1968. Possible use of translocations to fix desirable genes in insect pest populations. Nature, 218, 368-369. 
Curtis, C.F., 2003. Measuring public-health outcomes of release of transgenic mosquitoes. In: Takken, W. and Scott, T.W. eds. Ecological aspects for application of genetically modified mosquitoes. Kluwer Academic Publishers, Dordrecht, 223-234. Wageningen UR Frontis Series no. 2. [http://library.wur.nl/frontis/malaria/17_curtis.pdf]

Desowitz, R.S., 1993. The malaria capers: tales of parasites and people. W.W. Norton \& Company, Inc., New York.

Gaskell, G., Thompson, P.B. and Allum, N.C., 2002. Worlds apart? public opinion in Europe and the USA. In: Bauer, M.W. and Gaskell, G. eds. Biotechnology: the making of a global controversy. Cambridge University Press, Cambrdge, 351375.

Ito, J., Ghosh, A., Moreira, L.A., et al., 2002. Transgenic anopheline mosquitoes impaired in transmission of a malaria parasite. Nature, 417 (6887), 452-455.

Klassen, W. and Curtis, C.F., in press. History of the sterile insect technique (SIT). In: Dyck, V.A., Hendrichs, L. and Robinson, A.S. eds. The Sterile Insect Technique: principles and practice in area-wide integrated pest management. Springer.

Knipling, E.F., 1955. Possibilities of insect control or eradication through the use of sexually sterile males. Journal of Economic Entomology, 48, 459-467.

Knols, B.G.J. and Scott, T.W., 2003. Discussion - Ecological challenges concerning the use of genetically modified mosquitoes for disease control: synthesis and future perspectives. In: Takken, W. and Scott, T.W. eds. Ecological aspects for application of genetically modified mosquitoes. Kluwer Academic Publishers, Dordrecht, 235-242. Wageningen UR Frontis Series no. 2. [http://library.wur.nl/frontis/malaria/18_discussion.pdf]

Kristan, M., Fleischmann, H., Della Torre, A., et al., 2003. Pyrethroid resistance/susceptibility and differential urban/rural distribution of Anopheles arabiensis and An. gambiae s.s. malaria vectors in Nigeria and Ghana. Medical and Veterinary Entomology, 17 (3), 326-332.

Laven, H., 1967. Eradication of Culex pipiens fatigans through cytoplasmic incompatibility. Nature, 216 (113), 383-384.

Laven, H., 1972. Eradicating mosquitos using translocations: a first field experiment. Nature, 236, 456-457.

Lounibos, L.P., 2003. Genetic-control trials and the ecology of Aedes aegypti at the Kenya coast. In: Takken, W. and Scott, T.W. eds. Ecological aspects for application of genetically modified mosquitoes. Kluwer Academic Publishers, Dordrecht, 33-43. Wageningen UR Frontis Series no. 2. [http://library.wur.nl/frontis/malaria/04_louribos.pdf]

Macer, D., 2003. Ethical, legal and social issues of genetically modified disease vectors in public health. UNDP/WORLD BANK/WHO Special Programme for Research and Training in Tropical Diseases (TDR), Geneva, TDR/STR/SEB/ST/03.1.

[http://www.who.int/tdr/publications/publications/pdf/seb_topic1.pdf]

Msangi, A.R., Saleh, K.M., Kiwia, N., et al., 2000. Success in Zanzibar: eradication of tsetse. In: Tan, K.-H. ed. Area-wide control of fruit flies and other insect pests. Penerbit Universiti Sains Malaysia, Pulau Penang, 57-66.

Mshinda, H., Killeen, G.F., Mukabana, W.R., et al., 2004. Development of genetically modified mosquitoes in Africa. Lancet Infectious Diseases, 4 (5), 264-265.

National Research Council NRC, 1996. Understanding risk. informing decisions in a democratic society. National Academy Press, Washington. 
Oh New Delhi, Oh Geneva (editorial), 1975. Nature, 256, 355-357.

Olson, K.E., Higgs, S., Gaines, P.J., et al., 1996. Genetically engineered resistance to dengue-2 virus transmission in mosquitoes. Science, 272 (5263), 884-886.

Pew Initiative on Food and Biotechnology, 2005. Biotech bugs: a look at the science and public policy surrounding the release of genetically modified insects; conference proceedings, September 20-21, 2004, Washington D.C. [http://pewagbiotech.org/events/0920/Bugs-English-Final.pdf]

Scott, T.W., Takken, W., Knols, B.G.J., et al., 2002. The ecology of genetically modified mosquitoes. Science, 298 (5591), 117-119.

Spielman, A., Beier, J.C. and Kiszewski, A.E., 2002. Ecological and community considerations in engineering arthropods to suppress vector-borne disease. In: Letourneau, D.K. and Burrows, B.E. eds. Genetically engineered organisms: assessing environmental and human health effects. CRC Press, Boca Raton, 315-329.

Taylor, C.E. and Manoukis, N.C., 2003. Effective population size in relation to genetic modification of Anopheles gambiae sensu stricto. In: Takken, W. and Scott, T.W. eds. Ecological aspects for application of genetically modified mosquitoes. Kluwer Academic Publishers, Dordrecht, 133-146. Wageningen UR Frontis Series no. 2. [http://library.wur.nl/frontis/malaria/10_taylor.pdf]

Touré, Y.T., Dolo, G., Petrarca, V., et al., 1998. Mark-release-recapture experiments with Anopheles gambiae s.l. in Banambani Village, Mali, to determine population size and structure. Medical and Veterinary Entomology, 12 (1), 7483.

Touré, Y.T. and Knols, B.G.J., in press. Genetically engineered mosquitoes: requirements to be considered before field releases to control diseases. In: Boëte, C. ed. Malaria control with genetically modified mosquitoes. Landes Biosience, Georgetown.

WHO, 1976. WHO-supported collaborative research projects in India: the facts. WHO Chronicle, 30 (4), 131-139. 